\title{
Conflicto armado y medios corporativos. El caso del Ejército de Liberación Nacional (ELN)
}

\author{
Alexander Trujillo Baca ${ }^{1}$ \\ Universidad Surcolombiana, Colombia \\ alexander.trujillo@usco.edu.co
}

Cuando en la década de 1960 corría por Colombia los ideales cubanos que fortalecerían los orígenes campesinos y revolucionarios del Ejército de Liberación Nacional (En adelante, ELN), la prensa completaba más de un siglo narrando ideales políticos de la República, la radio más de dos décadas emitiendo su señal por el territorio (a través de la Radio Nacional de Colombia) y la televisión escasos años (con Televisión Comercial -TVC-) proyectando en la pantalla a blanco y negro los rostros del país y sus guerras.

Las historias del conflicto armado que por décadas fueron "un voz a voz", un rumor, un comentario, un mito, una leyenda, serían deconstruidas y reconstruidas por los medios de comunicación que a través de los años han pasado de mostrar al ELN como un puñado de campesinos, bandoleros, revolucionarios, a un grupo de actores armados narcoterroristas. ¿Cómo los medios de comunicación corporativos han construido al ELN como sujeto político?

En esencia el ELN se caracteriza por ser un grupo subversivo singular por una combinación política ideológica, el marxismo-leninismo y la revolución cubana, con "profundo alcance a nivel político trabajando sus bases sociales en las zonas del país en las que opera". Su lucha política-militar de medio siglo nació marcada por una fuerte influencia religiosa, entre sus figuras "más emblemáticas, los sacerdotes Camilo Torres (1929-1966) y Manuel Pérez (1943-1998), exponentes de la Teología de la Liberación (TL), una corriente nacida en el seno de la Iglesia católica en Latinoamérica con fuerte acento en acercarse a los pobres". Además de estas influencias religiosas, "sectores universitarios y miembros radicales del Partido Liberal colombiano -inspirados en la figura de Ernesto 'Che' Guevara- conformaron desde sus inicios este grupo guerrillero"' (El País, 2014).

Más que unos medios de comunicación que satisfacen el "derecho ciudadano a recibir información veraz" sin "ceñirse a la inspección o a la censura del Estado" (Torres Vásquez, 2013 p.124), los medios de comunicación en Colombia han construido un imaginario colectivo a partir del miedo. Aunque el conflicto armado siempre estuvo ahí, principalmente en las zonas rurales, la incursión de los medios en la privacidad del hogar posicionó en un primer momento la idea de un aumento de la violencia, la criminalidad y la inseguridad, a partir de lo cual los miedos se convirtieron en la clave de los nuevos modos de habitar y de comunicar. Esta clase de dinámicas, según Barbero (2015), transmite una angustia honda, una angustia cultural "que proviene de la pérdida del arraigo colectivo en unas ciudades en las que un urbanismo salvaje -pero que, a la vez, obedece a un cálculo de racionalidad formal y comercial- va destruyendo poco a poco todo paisaje de familiaridad en el que pueda apoyarse la memoria colectiva. Y, en segundo lugar, es una angustia producida por la manera como la ciudad normaliza las diferencias"' (p.18).

Se trata de medios de comunicación anclados a la tradición política conservadora, de derecha y extrema derecha, y posteriormente al capital

1 Profesor de Periodismo en la Universidad Surcolombiana, Máster en Periodismo Digital de la Universitat Oberta de catalunya y Doctorando en Comunicación de la Universidad Nacional de La Plata-Argentina. 
financiero y económico (Grupo Santo Domingo y Ardila Lule) que profesa ideales de la misma corriente política, y que han despojado al conflicto armado de su naturaleza política y social. Presentando a grupos armados, como el ELN, como actores que actúan con intereses individuales, contra la "democracia" entendida como un estado de prosperidad absoluta en la que como ciudadanos deben limitarse a elegir y ser regidos.

La Federación Internacional de Prensa de los Pueblos, a través del documento "Medios de comunicación en Colombia: las transformaciones que hacen falta" de Pablo Losana, afirma que al igual que la tierra los medios de comunicación están concentrados en pocas manos de carácter masculino, lo que limita sobre los derechos fundamentales a las mayorías. "Los dueños de la tierra y los dueños de los medios se garantizan, así, los resortes estratégicos del poder económico, político e ideológico sobre el que edifican una estructura social desigual e injusta desde la raíz" (Solana, 2017). Es decir, el 1\% de las familias más adineradas del país que concentran aproximadamente el $60 \%$ de la tierra apta para producir, tienen el control de los medios de comunicación en Colombia.

Este panorama de concentración mediática lo alimenta el informe Monitoreo de medios, realizado por Reporteros Sin Fronteras, que idéntica a las organizaciones empresariales Sarmiento Angulo, Ardila Lulle y Santo Domingo, comolos tres gruposempresariales que concentran el 57\% del total de los contenidos en radio, $\mathrm{TV}$, internet o prensa. "Esta concentración se agrava porque estas empresas son, además, dueñas de otros resortes estratégicos del poder económico" (Solana, 2017).

Lo anterior, se comprende gracias a la teoría de la Agenda Setting, explicada por López García (2006) como "la idea de que el público se basa casi exclusivamente en las fuentes de información proporcionadas por los medios de comunicación de masas para configurar una realidad cognoscible" (p. 39).
En este contexto mediático se puede decir que la guerrilla del ELN ha recibido un tratamiento mediático para nada apartado de ideales, líneas editoriales y punto de vista de dirigentes y profesionales de los medios. Es decir, la construcción del discurso mediático se realiza "sin tener en cuenta que los intereses que defienden unos y otros no son necesariamente los mismos" (Barreto, 2009). La sociedad no ha contado con los suficientes elementos para construir un concepto de este actor y por ende del conflicto que irónicamente han tenido que vivir en sus contextos, principalmente los escenarios rurales.

Sucede entonces que la filosofía de la industria mediática está más afín a los mismo valores de la confrontación armada que reza, según Karl Von Clausewitz, "la guerra es un acto de fuerza para imponer nuestra voluntad al adversario", lo que quiere decir que, con su discurso los medios de comunicación despojan al conflicto de su carácter político y social, minimiza los impactos de este sobre la sociedad y se dedican exclusivamente a presentar las acciones militares de una de las partes del conflicto, en este caso el ELN. A raíz de este sesgo frente al conflicto armado los procesos de negociación y las garantía para evitar acciones de lesa humanidad contra las comunidades pasan a un segundo plano. Más cuando es una realidad que el ELN sustenta su lucha contra el estamento en las bases sociales, el empoderamiento y liderazgo de las comunidades en la periferia del campo y la ciudad.

Los medios de comunicación en el país también han sido responsables de la deshumanización del conflicto y la agudización de los efectos colaterales de la confrontación en la cual se encuentra inmersa la sociedad, es decir, "existe una discriminación contra los opositores, a los que, inclusive, se les atribuye un carácter criminal"; también, "la relación de poder y el desconocimiento de los demás problemas ocasiona que estos no se resuelvan o se postergue su solución en tanto que hay prioridades referidas a la seguridad." (Torres Vásquez, 2013, p. 130) 
Una tendencia de esta peligrosa actuación de los medios, es la criminalización de la protesta popular pacífica. El modus operandi se da con despliegues mediáticos donde se vincula el inconformismo de los ciudadanos llevados a las calles (marchas, taponamientos, bloqueos) con el grupo subversivo. Un ejemplo de ello, en el que no se evidencia ninguna prevención por la seguridad del ciudadano, ocurrió en la publicación del Espectador el 6 de junio de 2016 sobre el paro agrario con expresiones como: "ELN busca presionar inicio de diálogos de paz con actos violentos en paro agrario". La anterior afirmación realizada por el Ministro de Defensa colombiano, Luis Carlos Villegas, y citada por el medio, termina poniendo en un mismo lado a campesinos, indígenas y guerrillas, lo que insta a la persecución del liderazgo social de por sí atacado constantemente en el país por grupos de extrema derecha. Se trata de calificativos y acciones que normalmente se pueden ver en boletines de resultados de las fuerzas militares y de policía.

Otra tradicional relación que realizan las instituciones del Estado de la sociedad civil con el ELN queda en evidencia en la publicación de la Emisora Blu Radio el 9 de junio de 2016, titulada "En los disturbios de la Univalle abrían infiltrados del ELN": general Ramírez. En este caso, aunque el medio no se atreve asegurar, no deja de ser alarmante la asociación, toda vez que el supuesto es inmediatamente eliminado por la fuente que consulta el medio y que en un tono autoritario, que no se detiene en el análisis, la investigación, pone en el mismo nivel a estudiantes de la Universidad con los guerrilleros; esto en un ambiente de completo desamparo estatal se traduce en un riesgo latente. "Los responsables de las protestas que realizan personas encapuchadas en la Universidad el Valle no solo serían estudiantes de la institución, manifiesta el comandante de la Policía de Cali, general Nelson Ramírez, que en estos desórdenes estarían infiltrados milicianos de grupos guerrilleros", antepone el medio. Por su parte el Comandante afirma: "Deben ser milicianos de grupos guerrilleros, podrían ser del ELN que son quienes están en este momento generando algún tipo de actos vandálicos $\mathrm{y}$ terroristas, no se descarta que en la Universidad estén estas personas".

Relacionar el uso de artefactos como las populares "papas bomba", "bombas molotov", de fabricación artesanal, con "artefactos explosivos artesanales", sube el nivel de protesta a beligerancia de un actor armado. "Se prepararon con bombas molotov y con algunos tarros pequeños de compota llenos de metralla que fueron lanzados contra la humanidad de nuestros policías", dice el comandante Ramírez, que inmediatamente anuncia el interés de acceder al campus para realizar controles.

Destacar el estamento sobre las bases sociales y sus expresiones contra hegemónicas, es todo "un programa criminal proclive necesariamente a aumentar el poder de la clase gobernante, por lo tanto, son un instrumento de poder de corte político e ideológico entre otros fines. Así pues, esta es una sociedad con una pedagogía violenta en la solución de problemas de tipo social, en la que los MMC (Medios Masivos de Comunicación) se convierten en formadores, que se circunscriben en 'educadores' principales, casi exclusivos, de una sociedad sin una cultura política, que permita discernir entre la información veraz e imparcial y aquella que no lo es" (Torres Vásquez, 2013).

De acuerdo con Borja Orozco, et al. (2008) tanto el discurso del gobierno como el de las Autodefensas Unidas de Colombia (AUC), grupo paramilitar de extrema derecha, recurre principalmente a la categoría de proscripción, aquella que categoriza a contradictores políticos y armados como violadores de normas sociales. "Mientras que las AUC hace referencia a las armas (no convencionales) utilizadas por el adversario y caracteriza negativamente las acciones realizadas por éste, el gobierno hace énfasis tanto en los rasgos de personalidad negativos como las acciones proscritas perpetradas por el adversario".

Este discursodeslegitimador deladversariopor parte del Estado -reproducido fidedignamente por los medios de comunicación- define los límites del orden legal (criminaliza) a los grupos 
que representan una amenaza para el orden social establecido, y por ende, para la estructura de autoridad, comunicando explícitamente a la sociedad la necesidad de medidas de control, "que incluyen el uso de la fuerza por la policía o por las fuerzas militares, que garanticen reestablecer el orden alterado por las acciones violentas llevadas a cabo por estos grupos ilegales" (Orozco, et al., 2009).

Discurso anticomunista estatal que coincide con el brote de paramilitarismo, que "invadió las distintas estructuras del poder estatal, en la perspectiva de configurarse como un proyecto político, militar, social y económico de alcance nacional. (...) el paramilitarismo ha privilegiado, como método de lucha, las masacres, asesinatos selectivos y desplazamientos de población civil, acusados de ser simpatizantes o colaboradores de las guerrillas" (Rivera, 2007).

Estas vertientes ideológicas antidemocráticas que han motivado la confrontación armada, son las mismas desde las cuales los medios de comunicación corporativos toman partido para representar en el imaginario social al ELN. Esta imagen a su vez ha sido la que limita la idea de construir paz pasando por la negociación política, la visibilización de los conflictos políticos, sociales, económicos, culturales, ambientales.

En palabras de Barbero (1998) "los medios no nos están ayudando a anclar en la historia lo que nos pasa, para desde allí dibujar algún futuro, sino que, en conjunto, los medios debilitan el pasado y diluyen la necesidad de futuro". Mientras la sociedad no tenga una versión amplia de la naturaleza y propósito de los actores del conflicto, no podrá considerar la pertinencia de su actuación en pro de la resolución del conflicto.

La comunicación que se hace del conflicto -en el caso puntual del ELN- no es aquella que intenta "enlazar los hechos, hilarlos, ponerlos en contexto", en cambio "trabajan sobre la simultaneidad de tiempos y la instantaneidad de la información que, posibilitadas por las tecnologías audiovisuales y telemáticas, se han convertido en perspectiva, esto es en modo de ver y de narrar" (Barbero, 1998)
En este sentido, la construcción política del ELN, como sujeto político, a través de los medios corporativos es una dinámica de regresión que, contraria a permitirnos comprender su ideología, aciertos, desaciertos y prospectivas - que lo ubiquen en la historia como un actor fundamental a tener en cuenta para la resolución del conflicto político, social y armado que vive Colombia hace más de 6 décadas-, lo despoja de su capacidad de disertación política, dejando de presente exclusivamente la vía armada contra su actuación beligerante.

En este siglo donde el rol del ciudadano es fundamental para la resolución de la confrontación, la superación de los mitos sobre los actores armados como el ELN es necesaria. Los medios deben empezar a liderar debates políticos e ideológicos que en el marco de la democracia y lejos del discurso del "enemigo interno" con ínfulas paramilitares, propicie el empoderamiento ciudadano más allá de la intención de asumir un rol beligerante para continuar alimentando fuerzas armadas contrainsurgentes. El futuro son las revoluciones sociales, culturales, educativas; es decir, dar por terminado el oscurantismo ideológico y mediático que no deja ser si se está del lado contrario.

\section{Referencias bibliográficas}

Martín Barbero, J. (1998). Medios: olvidos y desmemorias. Medios para la Paz. Tertulia en la Fundación Santillana. Recuperado de http:// www.brapci.inf.br/_repositorio/2010/01/pdf_ d74b341023_0007484.pdf

Barreto, I., Borja, H., Serrano, Y., \& LópezLópez, W. (2009). La legitimación como proceso en la violencia política, medios de comunicación y construcción de culturas de paz. Recuperado de http://www.redalyc.org/pdf/647/64712155013. pdf

Borja-Orozco, H., Barreto, I., Sabucedo, J. M., \& López-López, W. (2008). Construcción del discurso deslegitimador del adversario: gobierno y paramilitarismo en Colombia. Universitas Psychologica. Recuperado de http:// www.redalyc.org/html/647/64770220/ 
Calmon Alves, R. (2009). Impacto de las tecnologías digitales en el periodismo y la democracia en América Latina. Una reflexión en el contexto histórico de las redes sociales. En G. Franco. (Ed.), El impacto de las tecnologías digitales en el periodismo y la democracia en América Latina y el Caribe (pp. 6). Austin, Texas: Open Society Foundations Media Program.

El País. (2014). Conozca la historia del ELN, la guerrilla colombiana fundada por sacerdotes. Recuperado de http://www.elpais.com.co/ judicial/conozca-la-historia-del-eln-la-guerrillacolombiana-fundada-por-sacerdotes.html

López, García. G. (2006). Comunicación digital y líneas de fractura en el paradigma de la agenda setting. Doxa Comunicación. Volumen (4), 37-58.

Orozco, H. B., Barreto, I., Sabucedo, J. M., \& López, W. L. (2009). Construcción del discurso deslegitimador del adversario: gobierno y paramilitarismo en Colombia. Universitas Psychologica, 7(2), 584.

Rivera, E. D. J. V. (2007). History of the paramilitarismo in Colombia. História (São Paulo), 26(1), 134-153.

Solana, P. (2017). Medios de comunicación en Colombia: las transformaciones que hacen falta. Lanzas y Letras. Recuperado de http://lanzasyletras.org/2017/10/06/ medios-de-comunicacion-en-colombia-lastransformaciones-que-hacen-falta/ 


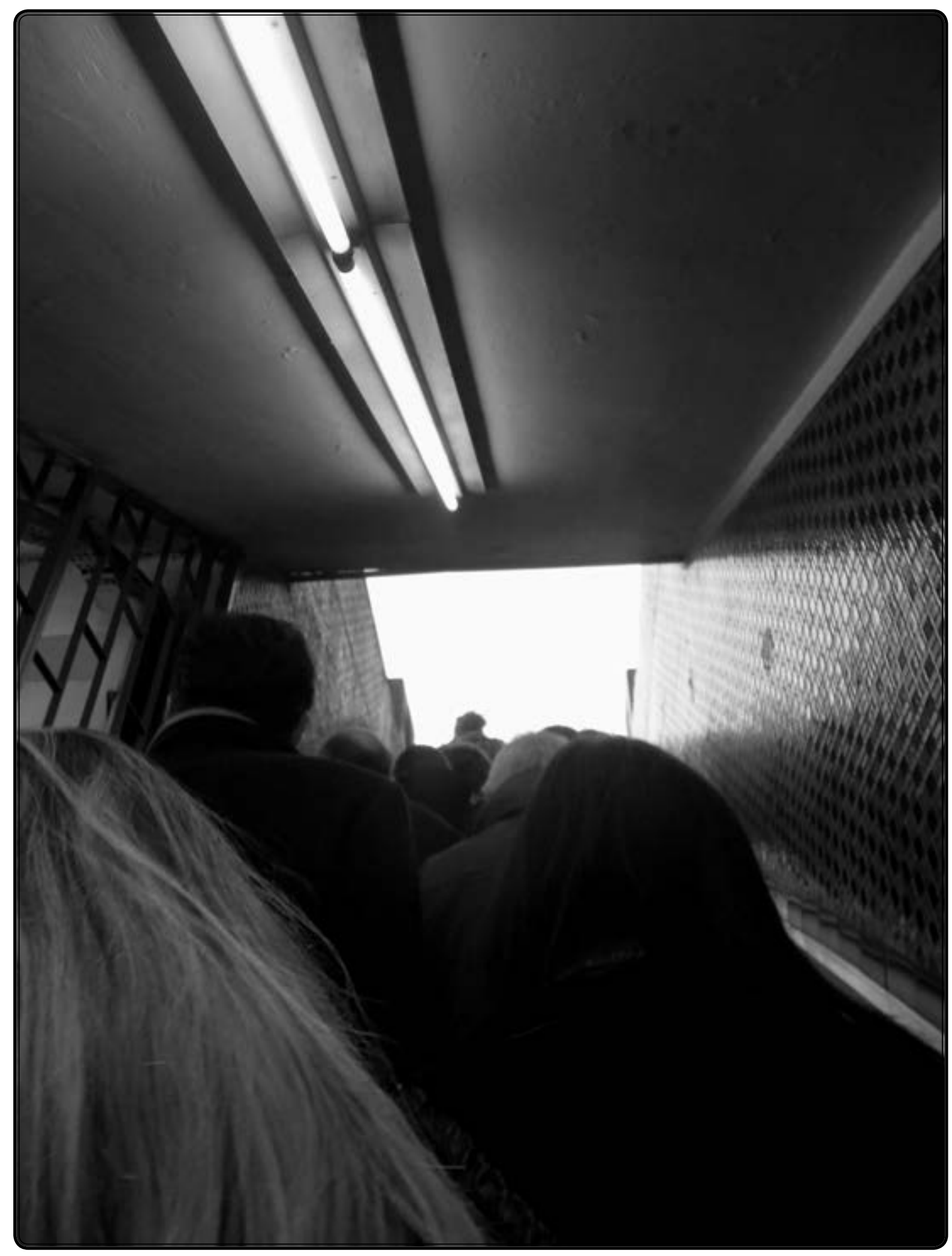

No hay luz al final del túnel. 